\title{
Investigation Food Diet of Cobitis taenia in Talar River (Mazandaran Province)
}

\author{
Soheil Bahrebar \\ Iranian National Institute for Oceanography, Tehran 1411813389, Iran
}

Received: August 8, 2012 / Published: December 20, 2012.

\begin{abstract}
Perch sweeper fish with scientific name Cobitis taenia is one of the Cobitidae family. Since this kind of fish lives in clean waters and in the high areas of Talar River, it can be an index on water implution. This survey on the diet of this specimen is done on two stations (Kaselian and Tajoon) and shallow and high areas of Talar River in Mazandaran (Southern part of Caspian sea) and the duration of this survey is from October 2008 till September 2009. We should mention that fishing was just done by electro-shocker with voltage $300 \mathrm{~V}$. And this fish after fishing is fixation in $10 \%$ formalin solution. So 410 perch sweeper fish were examined and the average of relatively length of gut (RLG) was $17.35 \mathrm{~cm}$. The index of vacated intestine (VI) was calculated $43.35 \%$ for all samples. From intense of diet points of view (GSI), the most frequency of full intestines was considered in summer and spring. On the other hand, the smallness of relatively length of gut index $(R L G<1)$ shows that perch sweeper fish's diet manner is inclined to herbivority. In the examination of containing of digestive track, overally 10 kinds of foodstuff were known. Based on amount of this index, $2.67 \%$ Chironomidae is known as main bait in all sampling period.
\end{abstract}

Key words: Perch sweeper fish (Cobitis taenia), diet, Mazandaran Talar River.

\section{Introduction}

Basically, in Caspian Sea ecosystem and its shedding basin, there are 78 species and 49 sub-species that belongs to 17 families. The family of perch sweeper fish involves small fishes (18 genera and 100 species) that 9 species of them are in Iran and one speices (with name of Cobitis taenia) perch sweeper fish (Fig. 1) is the only spice which is in Talar River. Dispersion of perch sweeper fish family, Cobitidae is reported in Caspian Sea and Dejle and Karoon River basins. From location points of view, the upper and median parts of rivers are preferred for living, which have stony river-bed (cold and full of $\mathrm{O}_{2}$ waters). These fishes are hidden under stones in day and are active at night. Most of them are hidden in habitant of rivers. At night, these fishes are hunting invertebrates and phytoplankton, small invertebrates

\footnotetext{
Corresponding author: Soheil Bahrebar, professor, research fields: fisheries, aquaculture. E-mail: bahrebar.soheil@gmail.com.
}

actively (with high activity) and eating them. These fishes are seen in Onchorinchous mykiss living places. So these groups of fishes are important for their beauty and keeping in aquarium [1].

They are baits for larger hunters specially, in sport fishing. So we select them for examination to get acquainted with dieting characteristics of this group, Cobitis taenia species (Fig. 1). These fishes have one row pharyngial tooth (more than eight in each row) and three pairs of barbels that its length is $12 \mathrm{~cm}$ (six in average) maximally. The growth of scale is recuced in them. This fish lives in clean and fresh waters and we can name them as an index of clean waters. This species are so compatible for living in Urasia (Asia) rivulets. Perch sweeper fish have the most diversity in South-Eastern of Asia

There is no survey about them in Iran. Since considering diet and selected foodstuff are important characteristics in ecology and biology of fishes, doing this survey regarding to perch sweeper fish in Caspian 


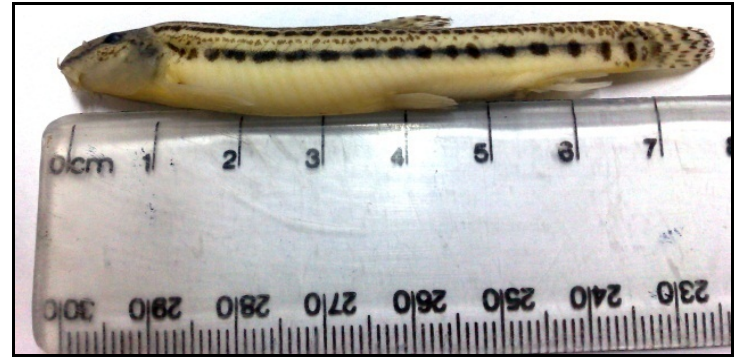

Fig. 1 Cobitis taenia.

Sea basins seems necessary. In this survey, diet of this species is studied in Southern basin of Caspian Sea (in Talar River).

\section{Materials and Methods}

This research was applied for one year from Oct. 2008 to Sept. 2009 in the Mazandaran Talar River (Fig. 2) and in two Kaselian and Tajoon stations (Figs. 3 and 4) which were located in the geographical limits between $36^{\circ} 31^{\prime} 4.57^{\prime \prime} \mathrm{N}$, and 52 $48^{\prime} 28.58^{\prime \prime} \mathrm{E}$ Southern district of Caspian Sea.

The samples were fished monthly in 12 months with electro-shocker with the voltage of $300 \mathrm{~V}$ and the force of $1.7 \mathrm{KW}$ with direct current.

The samples were transferred immediately after fishing lively to the fixative solution (formalin $10 \%$ ) for perusing the diets. In this method, the formalin entered through eating down into the fishes' digestive system and the effect of gastric juice on the stomach ingredients is prevented. After measuring the total length (TL) and standard length (SL) aiding caliper (resolution of 0.02 $\mathrm{mm}$ ), the fish weight was determined by the digital balance (resolution of $0.01 \mathrm{gr}$.).

Then the fish gut is exited and its ingredients aiding occurrence method, was recognized by numerical method for perusing the diet, therefore there is a close relation between food habits and the ratio of the gut length and fish's body length. Thus, by perusing the food habits of Cobitis taenia and determining the diet, it is utilized the relative index of gut length (the ratio between gut length and the total length) that is a suitable index for specifying the fish's diet nature [2].

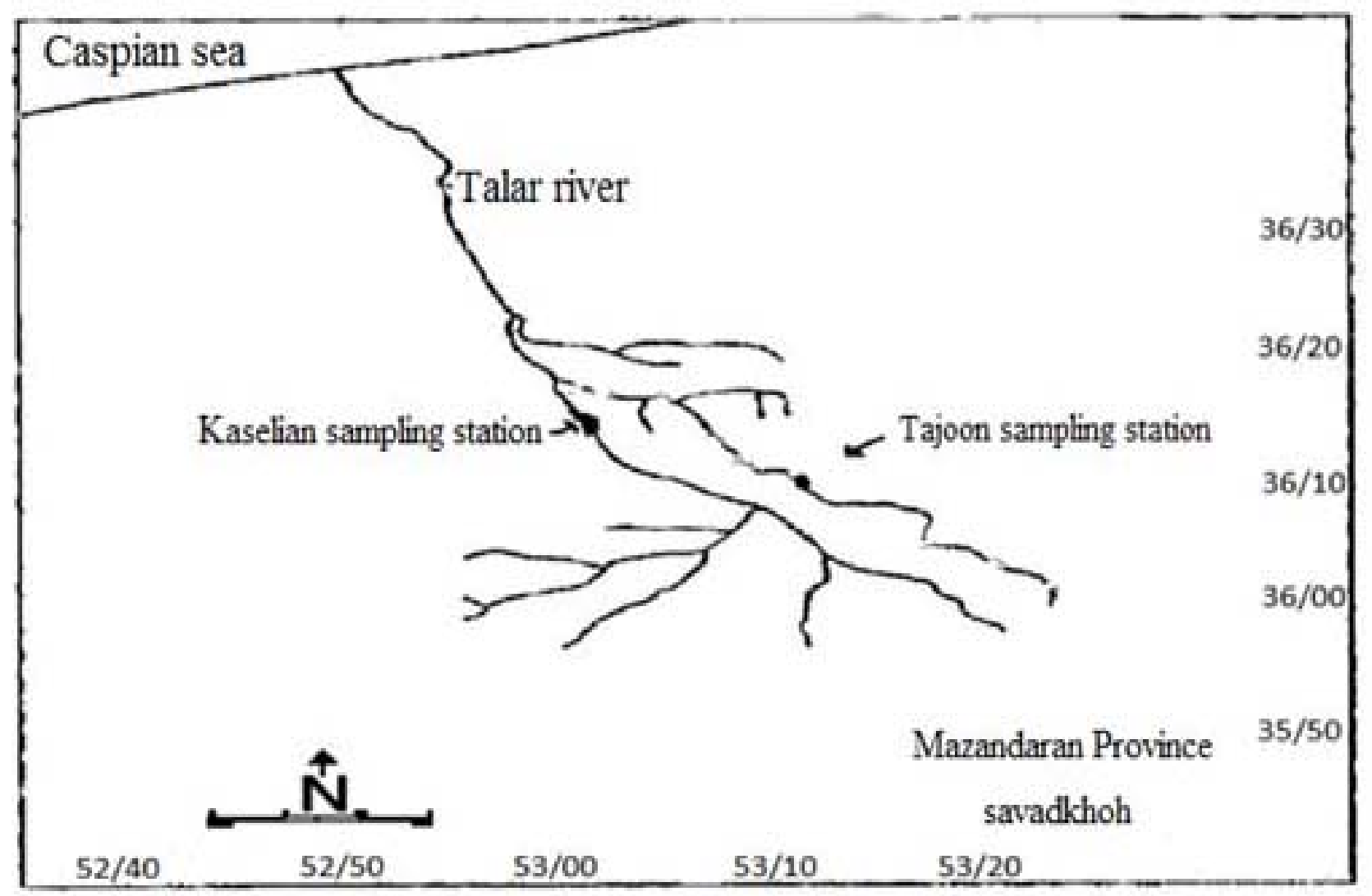

Fig. 2 Branches and stations of Talar River in the Mazandaran province (1:5000000). 


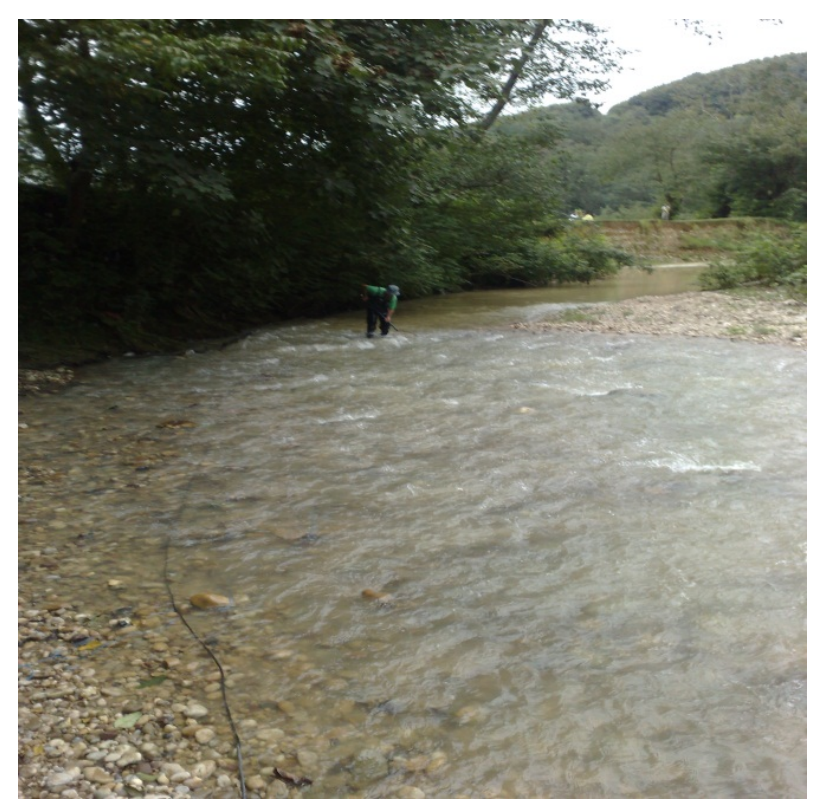

Fig. 3 Kaselian sampling station.

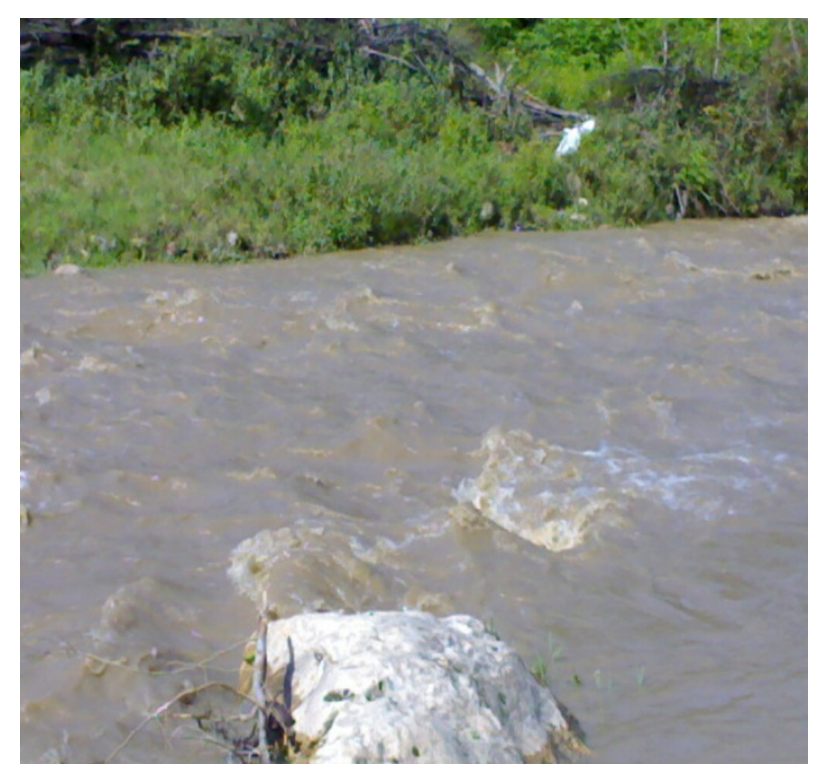

Fig. 4 Tajoon sampling station.

The following indexes were calculated in relation to the Cobitis taenia diet:

A. food preference index: for specifying the fish's type of food the relation 1 was applied:

Relation 1: $F_{p}=N s j \times 100 / N_{S}$

$F_{p}$ : the index of food preference;

Nsj: the numbers of the guts having prey;

$N_{S}$ : the numbers of total guts having food.

The relation between FP and food type is as follows:
If $F_{P}<10$ means that the eaten prey was accidental and is not considered as the aquatic food at all;

If $10 \leq F_{P}<50$, means that the eaten food $(j)$ is a second-rate food and this is applied in cases the main prey is not been available;

If $50 \leq F_{P}$, means that the said prey is the main food for fish.

B. gut vacuity index: is calculated on the relation 2:

Relation 2: VI $=E s \times 100 / T s$

$V I=$ the gut vacuity index;

Es: the number of vacant guts;

Ts: total perused guts.

The gut divided into three vacant, half-full and full. The criterion for being half-full and full is the existing food in the gut. The interpretation of the achieved VI amounts is specified under the following terms:

$0 \leq V I<20$ : the rational result is that the aquatic is gluttonous;

$20 \leq V I<40$ : the rational result is that the aquatic is relatively gluttonous;

$40 \leq V I<60$ : the rational result is that the aquatic has a middle nutrition;

$60 \leq V I<80$ : the rational result is that the aquatic is relatively abstemious;

$80 \leq V I<100$ : the rational result is that the aquatic is abstemious.

C. relative length of gut: is a suitable index in relation to the type or nature of the eaten food which is increased with increasing the herbal stuffs ration (relation 3), so that if the relative length of gut is less than 1 , the fish is carnivorous and if more than 1 , prone to vegetarian. The middle measure indicates that the fish is omnivorous. This index shall be calculated for the different length groups, for finding the relation between food habits [2].

Relation 3: relative length of gut $=$ total length/gut length.

D. gastro somatic index (GSI): was applied for estimating the fishes' nutrition intensity and was calculated on the relation 4 :

Relation 4: GSI = total fish weight/gonad weight. 
E. HI; hepato somatic index: is resulted from the following relation.

Relation 5: $H I=$ liver weight $/$ fish weight $\times 100$.

F. overweight index or condition factor Fultons: was calculated by relation 5 (Hill 16930).

Relation 6: $K=W / L^{3} \times 10^{3}$

In this relation:

$K=$ Overweight index;

$L=$ Total length $(\mathrm{cm})$;

$W=$ Weight $(\mathrm{g})$.

Comparing the average of GSI in the sampling different months via unilateral variance analysis, $T$-test and excel program and SPSS software was performed.

\section{Results and Discussion}

According to the biometric sample of Cobitis taenia which was collected during 12 months from Oct. 2008 to Sept. 2009, the total length (TL) average was 68.09 $\mathrm{mm}$, and the maximum and minimum observed length were recorded 97.30 and 30.40 in order.

The weight average of the samples was $2.42 \mathrm{~g}$. The maximum and minimum recorded weights were resulted in order 7.33 and $0.19 \mathrm{~g}$, respectively. The overweight average was calculated. The monthly biometric results of the samples were provided in the Table 1. The gut length index to the body length (RLG) was calculated averagely 1.93 (Figs. 1 and 2) and the gained result implies to being vegetarian the said species [3]. Regarding the nutrition intensity in the different months, the GSI sampling was calculated in the current stations (Figs. 3-5). The most amount of GSI in the different stations was seen in the March-April.

According to the above results, the most nutrition intensity is seen in the summer. Regarding full and vacant status of the perused guts, from 127 guts: 45 vacant, 38 half full and 44 full were diagnosed (Figs. 5-6). Therefore, the gut vacuity index for Cobitis taenia during the total sampling term was calculated $35.43 \%$ that introduces this species as a relatively gluttonous kind. The most full guts numbers in the April and the least in the January introduce the Cobitis taenia as a relatively gluttonous kind (Figs. 7-9).

The examination of the containing of sample's digestive tracks shows that this fish feed of 10 kinds of foodstuff in the sampling period.

Known foodstuffs based on preference index and frequencies are as follow:

(1) Chironomidae with $67.02 \%$;

(2) Small worm (oligochaeta) with $21.28 \%$;

(3) Ostracode with $4.79 \%$;

(4) Nemathelminthes (nematode) with $1 / 60 \%$;

(5) One kind of fresh waterspider with $1.60 \%$;

(6) Insect (Baetis) with 1.06\%;

(7) Fish larve with $1.06 \%$;

Table 1 The results of total length (TL), standard length (SL) factors and the Cobitis taenia weight's in the sampling different months in the Talar River in 2009.

\begin{tabular}{llllllllll}
\hline & \multicolumn{3}{l}{ Weight $(\mathrm{g})$} & \multicolumn{3}{c}{ Standard length $(\mathrm{cm})$} & \multicolumn{3}{c}{ Total length $(\mathrm{cm})$} \\
\hline Max. & Average & Min. & Max. & Average & Min. & Max. & Average & Min. & Month \\
\hline 5.39 & 3.53 & 1.14 & 74.00 & 63.54 & 48.80 & 86.70 & 72.90 & 52.30 & Mar. \\
3.14 & 1.60 & 0.59 & 71.60 & 52.77 & 39.80 & 84.40 & 63.43 & 20.46 & Apr. \\
3.90 & 1.69 & 0.89 & 71.20 & 50.92 & 40.80 & 82.60 & 60.32 & 52.30 & May \\
5.85 & 2.22 & 0.82 & 81.30 & 54.14 & 38.60 & 90.50 & 64.83 & 46.60 & June \\
3.59 & 1.50 & 0.25 & 72.20 & 52.93 & 39.00 & 82.00 & 63.05 & 44.80 & July \\
4.60 & 1.82 & 1.07 & 74.60 & 54.25 & 41.20 & 84.90 & 64.05 & 51.40 & Aug. \\
5.00 & 1.96 & 0.52 & 74.10 & 61.03 & 43.10 & 85.6 & 70.71 & 3.56 & Sept. \\
5.77 & 2.89 & 0.74 & 74.10 & 60.74 & 42.60 & 85.60 & 70.04 & 52.20 & Oct. \\
5.48 & 2.09 & 0.51 & 72.60 & 55.27 & 33.20 & 86.20 & 64.95 & 38.40 & Nov. \\
5.70 & 2.52 & 0.41 & 78.60 & 59.89 & 32.60 & 83.90 & 70.24 & 38.40 & Dec. \\
7.33 & 2.69 & 0.92 & 85.70 & 80.59 & 42.80 & 97.30 & 69.11 & 51.80 & Jan. \\
6.08 & 2.16 & 0.19 & 77.60 & 52.32 & 26.80 & 94.30 & 62.04 & 30.40 & Feb. \\
\hline
\end{tabular}




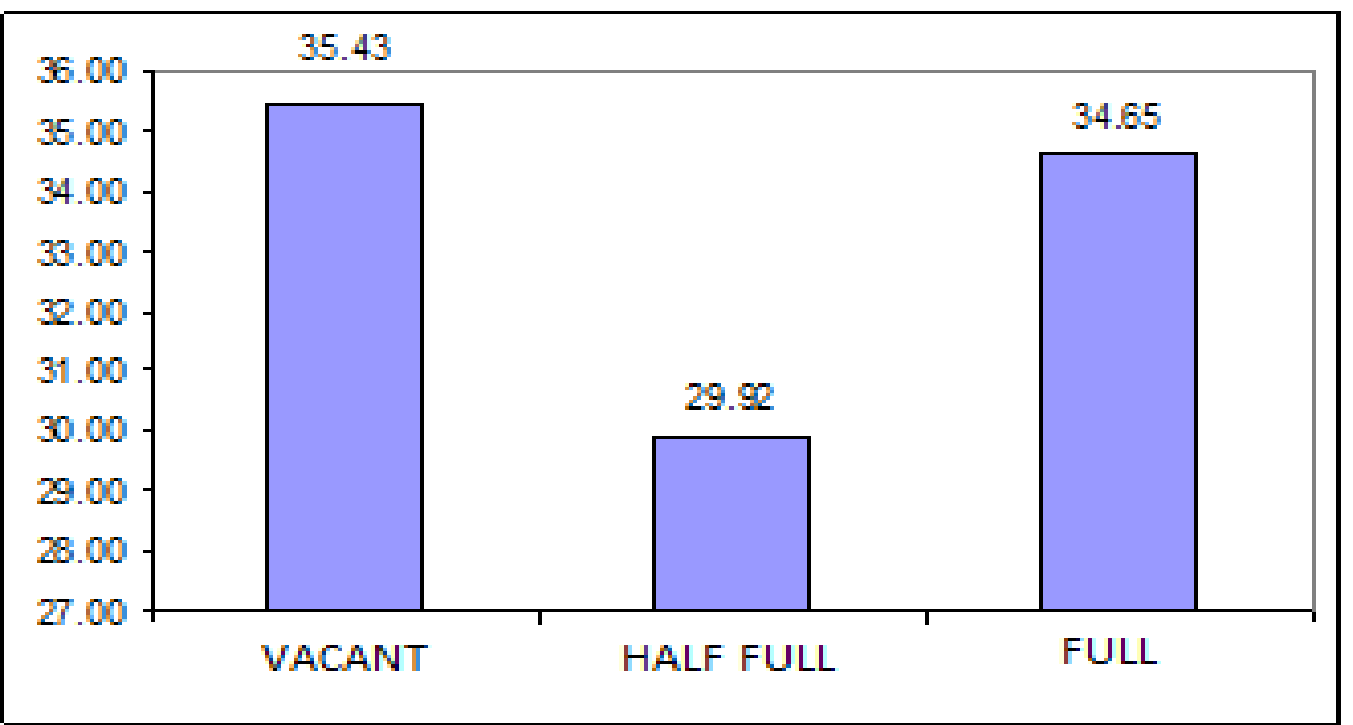

Fig. 5 Total situation of considered intestines of perch sweeper fish in Talar River in 1388.

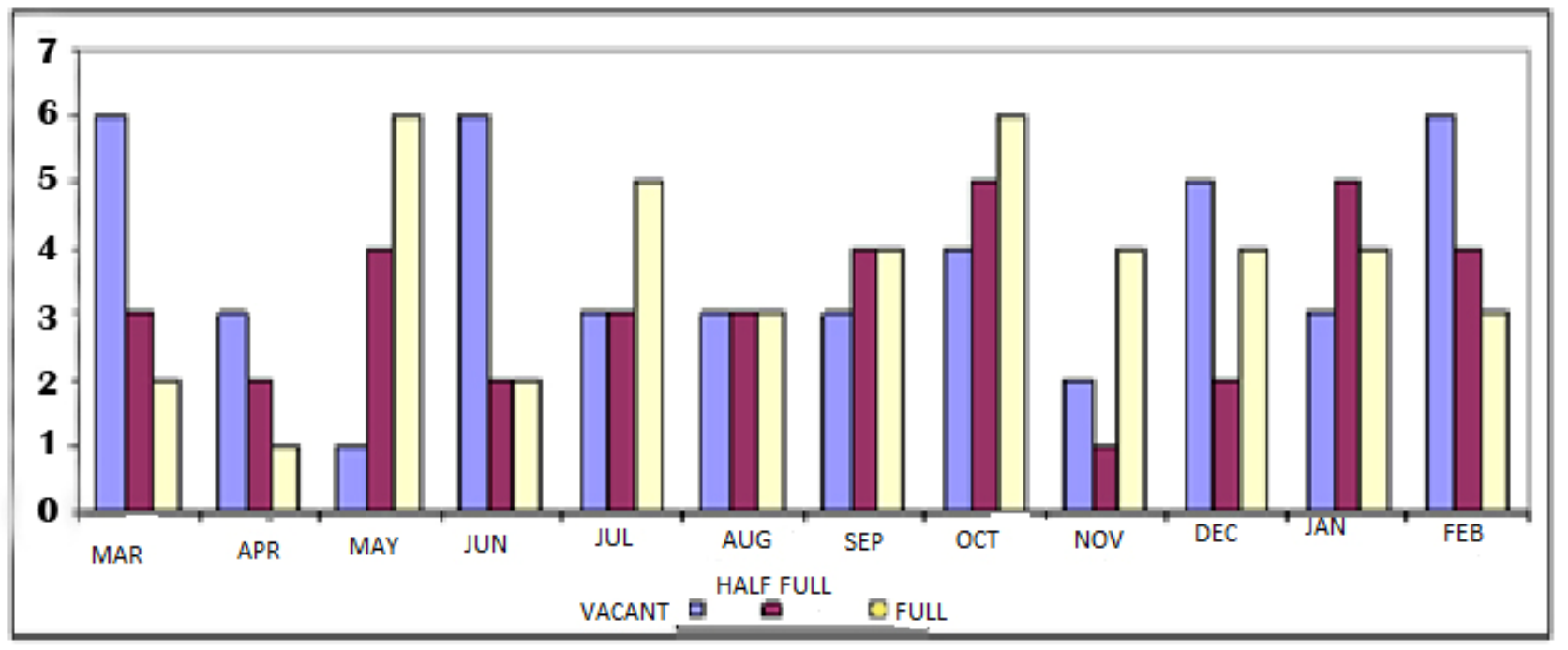

Fig. 6 Total situation of considered intestines of perch sweeper fish based on sampling months in Talar River in 1388.

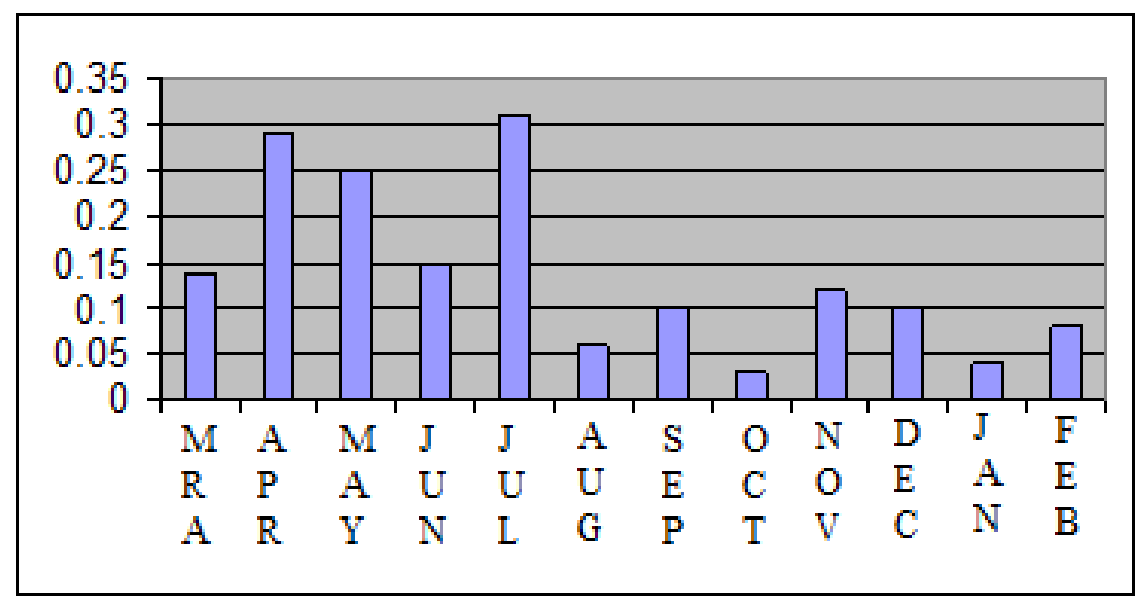

Fig. 7 Amounts of GSI index of perch sweeper fish in Kaselian station in sampling months in 1382. 


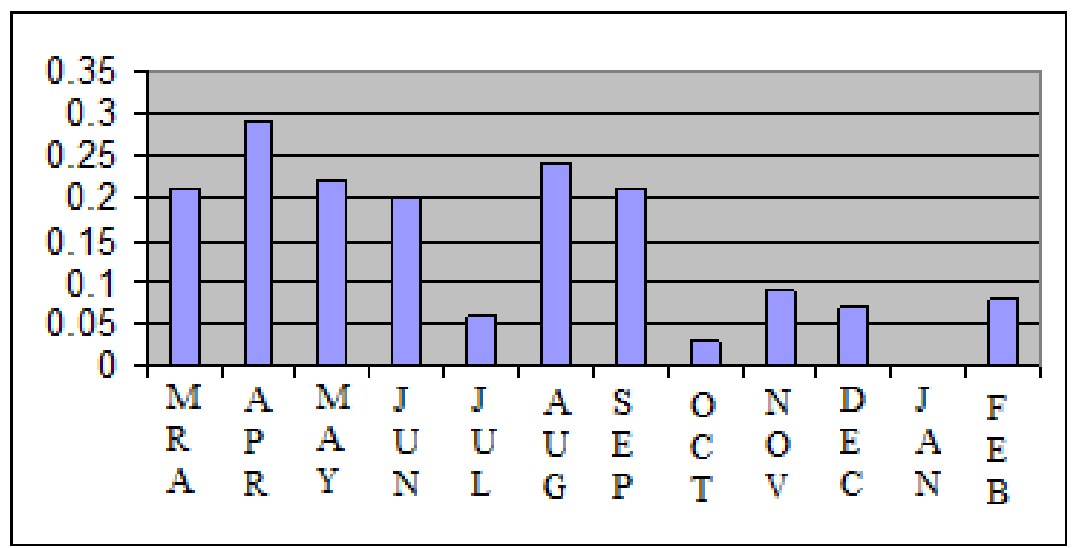

Fig. 8 Amounts of GSI index of perch sweeper fish in Tajoon station in sampling months 1382.

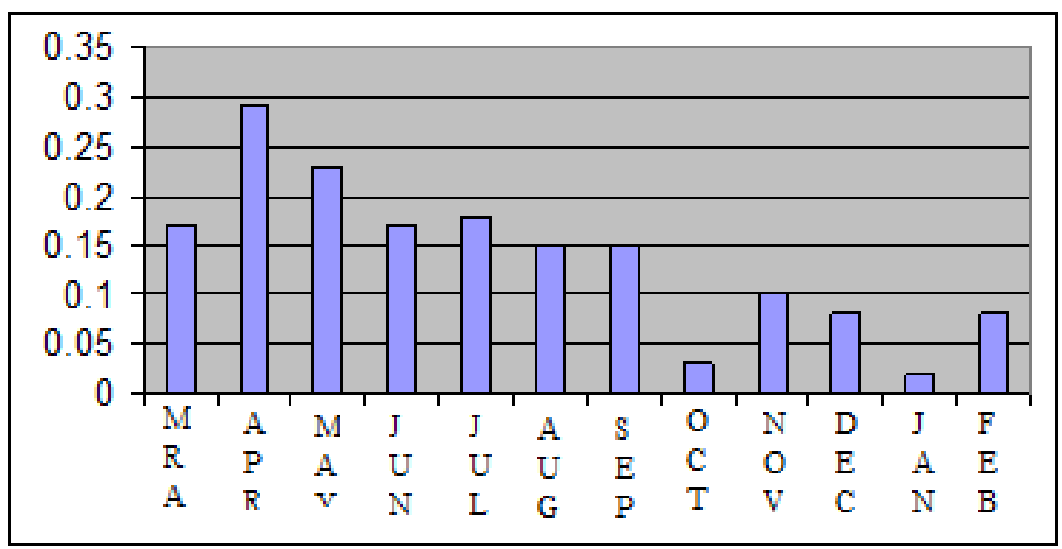

Fig. 9 Amounts of GSI index of perch sweeper fish in sampling months 1382.

(8) Aspergilus algae with $0.53 \%$;

(9) Fish egg with $0.53 \%$;

(10) Hydropsic pupa with $0.52 \%$.

Thus the main bait of this fish is Chironomidae, Figs. 10 and 11 show these subjects in all seasons.

\section{Conclusions}

Since the calculated relative length of gut index (RLG) for perch sweeper fish is more than one and there is a significant difference between diverse linear groups and between winter and fall with spring and summer, so the diet of this species is inclined to herbivority [4]. The average of VI index was $35.43 \%$ during sampling period that Cobitis taenia was in perusing the guts abundance, the gut relative length was announced $34.95 \mathrm{~mm}$, as well in regard to the existence of foodstuffs; $34.65 \%$ of the guts were full, $29.92 \%$ were half-full and $35.43 \%$ were recorded vacant. As regards gut vacuity and full, the more abundance of full guts was seen during the April and November [5].

Upon perusing the ingredients of digestion system, 10 kinds of foodstuffs were recognized, in order to the abundance including: 1-Chironomid, 2-Oligochaeta, 3-StraKoud, 4-Nematod, 5-a kind of aquatic arachnid, 6-Spirogyra thallyphyte, 7-Hydropsic pupa, 8-Baetis, 9-Laro fish, 10-Spawn, so that considering the food preference index $(F p)$, due to $50 \leq F P$, and the gained number was 64.56 , therefore the main prey, Chironomide with more than $67 \%$ was announced. The average overweight index in all sampling fishes in the Talar River was gained 82.78. The overweight of a fish varied through gonad seasonal changes as well the nutrition intensity. The overweight index, mentioning season, gender and the groups size and observing the weather is calculated, thus there is a little difference in $K$ quantity [6]. 


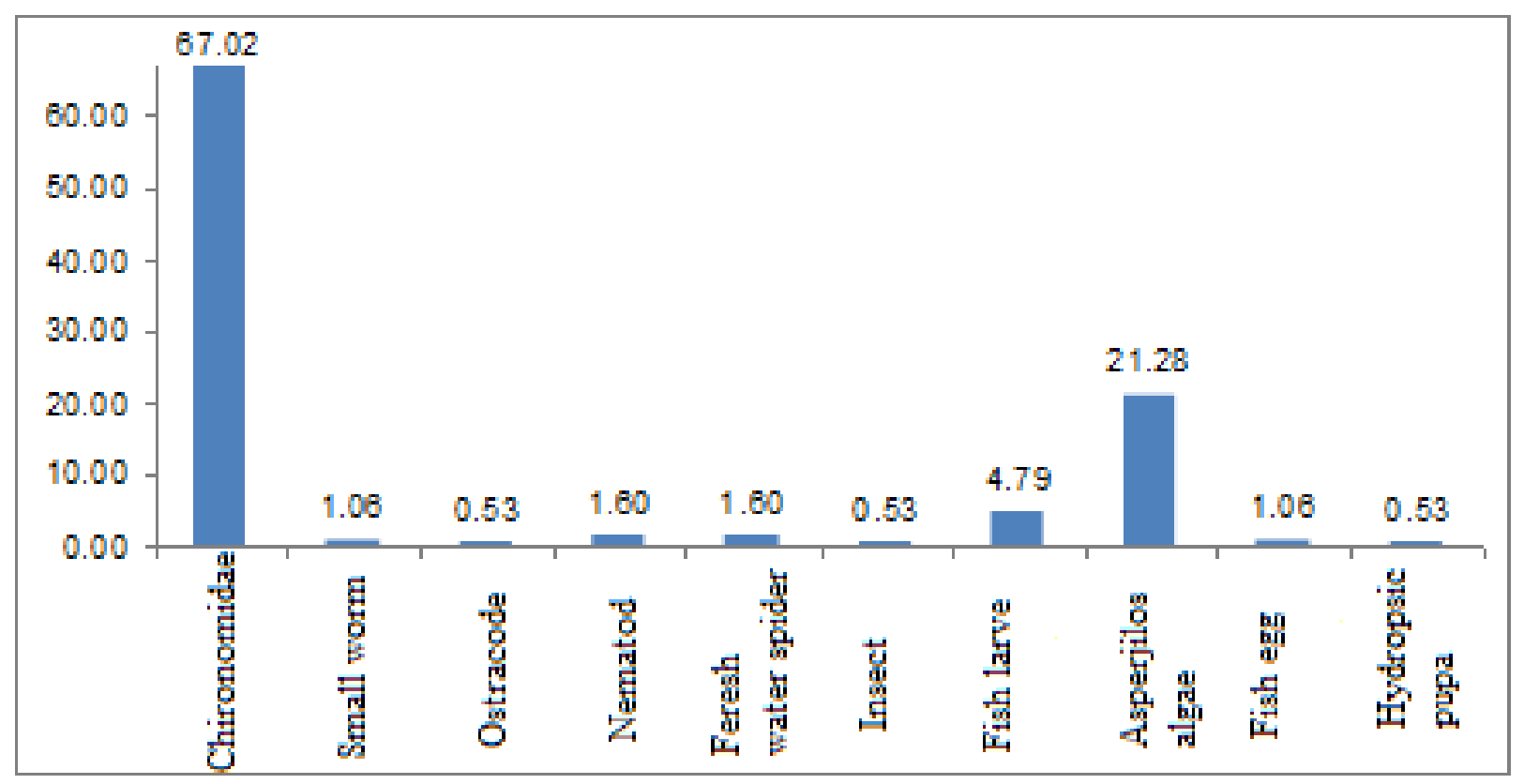

Fig. 10 Containing of perch sweeper fish intestine in Talar River 1388.
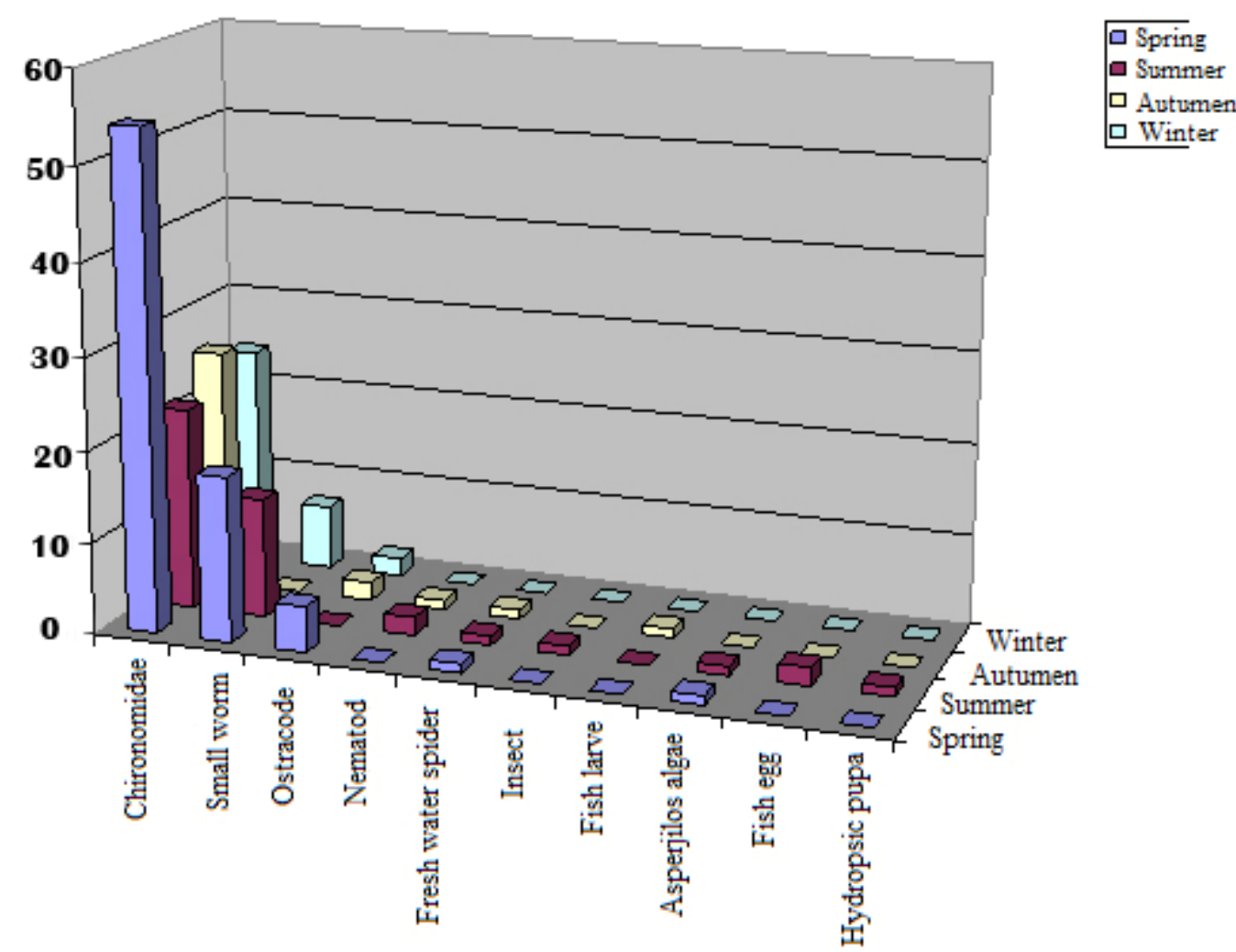

Fig. 11 Containing of perch sweeper fish intestine based on season in Talar River 1388.

Considering the situation and chute of the Talar River, includes shallow part and sand-stoning and cobblestone route, which provides a variety bed for
Bantus societies of shallow regions [7]. In the laboratorial researches, the extent of heterogenopoda fishing, by increasing the bed unevenness (The 
cobblestone increase ration to the gravel and sand) is reduced and the light intensity by influence on the bed thallophytic productions effects on the grazing invertebrates [8].

At the end, considering the importance of Cobitis taenia family, as respect to the aesthetic value and their application as the ornamental fishes in the aquariums, the more and extent studies in the field of recognizing and perusing the nutritive specifications of this species are suggested [9].

In comparing with the Tabiei [10] regarding Nemacheilusmalapterurus in the Zarringol Rriver of Golestan province, due to the small relative length gut $(R L G<1)$, it is indicated that the food habit of the Nemacheilusmalapterurus is carnivorousness and in this research the food preference of $N$. malapterurus (Chironomid) was specified with $65.34 \%$ abundance in the diet.

\section{References}

[1] S.P. Biswas, Manual of Methods in Fish Biology, South Asian Publisher, Pvt Ltd., New Delhi, 1993, p. 157.

[2] T.P. Diggings, J. Kauer, R.K. Chakrabroti, J.V. Depinto,
Diet choice by the exotic round goby (Neogobiusmelanostomus) as influenced by prey motility and environmental complexity, Journal of Great Lakes Research, 2002, pp. 411-442.

[3] O. Euzen, Food habits and diet composition of some fish of Kuwait, Kuwait Bulletin of Science 9 (1987) 65-85.

[4] W. Fischer, W. Bianchi, Marine resources service fishery resources and environment division, FAO Fisheries Department, Rome, Italy, 1984.

[5] A.H. Hussainy, On the functional morphology on the alimentary track of some fishes inrelation to difference in their feeding habits, Quart, 1949, pp. 190-240.

[6] B.H. Kiabi, A. Abdoli, M. Naderi, Status of the fish fauna in south Caspian Basin of Iran, Zoology in the Middle East, 1999, pp. 57-65.

[7] Y. Karakousis, C. Triantaphylidis, P.S. Economidis, Morphological variability amen seven populations of brown trout, Salmotrutta L., in Greece, Journal of Fish Biology, 1997, pp. 807-817.

[8] M. Pryzybylski, J. Banbur, Feeding Relations between the (Gudgen Gobio Gobio and the Stone Loch (NemacheilusBarbatulus), ActhHydrobiol, 1989.

[9] W.F. Royce, Biology of Aquatic Resource Organisms Introduction to the Practice of Fishery Science, Academic Press Inc., Chichester, 1994, pp. 132-179.

[10] R. Solow, A randomization test for misclassification probability, Discriminant Analysis Ecology, 1990, pp. 2379-2382. 